Check for updates

Cite this: RSC Adv., 2017, 7, 47456

Received 22nd July 2017

Accepted 25th September 2017

DOI: $10.1039 / \mathrm{c} 7 \mathrm{ra0} 8101 \mathrm{~d}$

rsc.li/rsc-advances

\title{
An electrogenerated base for the alkaline oxidative pretreatment of lignocellulosic biomass to produce bioethanol
}

\begin{abstract}
Tongjun Liu (D) *a and Zhenglong Li†*bc
In this study, we aimed to develop an alternative base to substitute for $\mathrm{NaOH}$ for use in alkaline oxidative biomass pretreatment. An electrogenerated base (EGB) from water electrolysis was employed in the alkaline oxidative pretreatment of corn stover (CS). Similar to $\mathrm{NaOH}$, when the EGB was used in pretreatment, $56.6 \%$ of the original lignin was removed after $6 \mathrm{~h}$ pretreatment, leading to significantly enhanced enzymatic digestibility. The glucan digestibility of the pretreated CS was 3.8 times higher than that of raw CS after $24 \mathrm{~h}$. The ethanol metabolic yields were $64.6 \%$ and $72.4 \%$ when using activated carbon detoxified hydrolysate or hydrolysate at $\mathrm{pH} 5.5$, respectively. These results demonstrate that an EGB, a byproduct from various electrocatalytic processes, could be used as a potential replacement for $\mathrm{NaOH}$. Moreover, we propose a new biorefinery concept, which combines water electrolysis, biological conversion and thermochemical/catalytic conversion to produce bioethanol, hydrogen, hydrocarbon fuels and valuable chemicals.
\end{abstract}

\section{Introduction}

Pretreatment plays a crucial role in the biological conversion of lignocellulosic biomass to biofuels and chemicals. ${ }^{1,2}$ Among the well-developed technologies, alkaline-based pretreatment has been considered as one of the most promising approaches, ${ }^{3,4}$ which can effectively improve the digestibility and fermentability of biomass. ${ }^{5,6}$ Alkaline oxidative pretreatment, one of the alkaline pretreatment methods, has been practiced for many years. ${ }^{7-12}$ This process can be carried out at ambient temperatures and pressures for relatively medium to long periods of time. In addition, its capital costs are much lower compared with other technologies, such as ammonia fiber expansion (AFEX) or steam explosion approaches. ${ }^{13,14}$ Also, low carbohydrate loss and high sugar conversion rates are other important advantages of this process. Chemicals such as $\mathrm{NaOH}, \mathrm{KOH}$, $\mathrm{Ca}(\mathrm{OH})_{2}$ and $\mathrm{Na}_{2} \mathrm{CO}_{3}$ have been tested as bases for alkaline oxidative pretreatment. ${ }^{15-18}$ Typically, there is a high consumption of base in such a pretreatment. For example, $126 \mathrm{~g}$ of $\mathrm{NaOH} / \mathrm{kg}$ biomass is used in alkaline oxidative pretreatment. ${ }^{6}$ Higher use of base has been also reported in other

${ }^{a}$ Department of Bioengineering, Qilu University of Technology, Jinan, 250353, China. E-mail: liutongjun@outlook.com

${ }^{b}$ Department of Chemical Engineering and Materials Science, Michigan State University, East Lansing, MI 48824, USA. E-mail: lizhenglong1982@gmail.com ${ }^{c}$ Department of Biosystems and Agricultural Engineering, Michigan State University, East Lansing, MI 48824, USA

$\dagger$ Current address: Energy and Transportation Sciences Division, Oak Ridge National Laboratory, 1 Bethel Valley Road, Oak Ridge, TN 37830, USA. studies. ${ }^{7,9,11,12,18-21}$ Yuan et al. ${ }^{22}$ used more than $80 \mathrm{~g}$ of $\mathrm{NaOH} / \mathrm{kg}$ biomass (dry basis) to perform a two-stage alkaline pretreatment. Large chemical consumption in alkaline pretreatment reduces the economic competitiveness of the method, ${ }^{18}$ and becomes one of the major hurdles for the commercialization of a biorefinery using alkaline pretreatment. ${ }^{23}$ Therefore, it is necessary to find a cost-effective alternative alkaline source, which would make this pretreatment much more economical and cost-competitive. In this study, we aimed to demonstrate a new concept, using an electrogenerated base (EGB) as an alkaline alternative in alkaline oxidative pretreatment.

An EGB can be produced in several electrochemical ways. One of the approaches is conventional water electrolysis using a two-chamber electrochemical cell. On the cathode side, the reduction of $\mathrm{H}^{+}$takes place, resulting in the continuous consumption of $\mathrm{H}^{+}$. On the anode side, the oxidation of water occurs, and $\mathrm{H}^{+}$is constantly produced. In most cases, when the $\mathrm{H}^{+}$consumption rate is much higher than the $\mathrm{H}^{+}$transfer rate from the anode to the cathode side, an alkaline solution will be produced on the cathode side, while an acidic solution will be produced on the anode side. ${ }^{24}$ This approach is mainly used to produce hydrogen from water, so this electrogenerated base is considered a by-product of electrochemical hydrogen production. Electrocatalytic hydrogenation has been studied as an important alternative to the thermal catalytic hydrogenation of biomass, ${ }^{25-30}$ and an electrogenerated base is also produced during this process as a by-product. Besides this, electrocatalytic oxidation on the anode side also generates a byproduct base in the cathode chamber. ${ }^{31,32}$ 
Previous studies have demonstrated the use of the electrogenerated acid solution for cellulose hydrolysis ${ }^{33}$ and the transformation of epoxides to ketones and acetonitrides ${ }^{34}$. However, very little attention is paid to the alkaline solution on the cathode side. Since this alkaline solution is considered a byproduct of water electrolysis, and electrocatalytic hydrogenation and oxidation, if it is used in biomass pretreatment, this will contribute to reducing the alkaline costs in biomass pretreatment. In particular, when renewable electricity (solar or wind derived) is used for these electrolytic reactions, ${ }^{35}$ the base supply will become more sustainable and environmentally friendly. Another direct approach is photocatalytic water splitting, which has been the focus of much research. ${ }^{36-39}$

To effectively use these electrogenerated bases (by-products from various electrocatalytic processes), we explored the feasibility of using an EGB from water electrolysis (for hydrogen production) as an alkaline source for alkaline oxidative biomass pretreatment. Enzymatic saccharification and ethanolic fermentation were subsequently conducted with genetically modified yeast. In view of the above mentioned idea, we also proposed an integrated biorefinery concept, combining water electrolysis, biological conversion and thermochemical/ catalytic conversion.

\section{Materials and methods}

\subsection{Feedstocks}

Corn (Zea mays L. Pioneer hybrid 36H56) stover (CS) was obtained from the Great Lakes Bioenergy Research Center (GLBRC), University of Wisconsin-Madison. The switchgrass (Panicum virgatum) variety was Cave-in-Rock, provided by the Michigan Biotechnology Institute (MBI). Samples were stored at room temperature. Biomass was ground in a mill (Thomas Scientific, Swedesboro, NJ) to pass through a $5 \mathrm{~mm}$ screen.

\subsection{Water electrolysis}

Water electrolysis was carried out in a two-chambered glass $\mathrm{H}$ cell, $^{30}$ separated by a DuPont ${ }^{\circledR}$ Nafion-117 membrane. To counter resistance heating as current passes through the electrolyte solution, a water jacket was used to cool the cathode chamber. The reaction temperature was maintained at $27{ }^{\circ} \mathrm{C}$, and the pressure was $1 \mathrm{~atm}$. $\mathrm{NaCl}$ served as the cathode electrolyte (catholyte), while ruthenium supported on activated carbon cloth was used as the working electrode (cathode). The anolyte $(30 \mathrm{~mL})$ consisted of $1 \mathrm{M}$ sulfuric acid, and a Pt wire was used as the counter electrode (anode). Electrolysis was carried out under galvanostatic control (480 mA) using an Instek GPR11H30D DC power supply.

\subsection{Pretreatment}

Pretreatment was conducted in a $1 \mathrm{~L}$ Erlenmeyer flask at $30{ }^{\circ} \mathrm{C}$ and $150 \mathrm{rpm}$. CS loading was $20.5 \%(\mathrm{w} / \mathrm{w})$. The $\mathrm{H}_{2} \mathrm{O}_{2}$ loading was $0.125 \mathrm{~g} \mathrm{~g}^{-1}$ of biomass. CS (100 g) was mixed well with base $\left(\left[\mathrm{OH}^{-}\right]=1.7 \mathrm{~mol} \mathrm{L^{-1 }}\right)$ generated from water electrolysis. Subsequently, $37.5 \mathrm{~mL}$ of a commercial solution of $30 \% \mathrm{H}_{2} \mathrm{O}_{2}$ (ACS Reagent Grade, J. T. Baker) was added into the slurry, and the $\mathrm{pH}$ was adjusted to 11.5 with the base solution. The $\mathrm{pH}$ was maintained at 11.5 via the manual addition of the same base solution periodically. During the addition of base, the biomass was thoroughly mixed.

\subsection{Enzymatic saccharification}

After pretreatment, the slurry was adjusted to $\mathrm{pH} 4.76$ using $72 \% \mathrm{H}_{2} \mathrm{SO}_{4}$. The enzyme protein loading was $30 \mathrm{mg} \mathrm{g}^{-1}$ of glucan of an optimized enzyme cocktail [Accellerase 1000, Multifect-xylanase, and Multifect-pectinase (Genencor, NY, USA) solutions, at a protein ratio of $0.63: 0.27: 0.1]$. The enzymes were added to the pretreated CS slurry, then mixed and incubated at $50{ }^{\circ} \mathrm{C}$ for $24 \mathrm{~h}$. The material was sampled at different intervals to determine the monomeric sugars content. Glucan conversion was calculated based on the glucan dissolved into the hydrolysate divided by the total glucan content in the CS.

\subsection{Detoxification of hydrolysate using activated carbon}

After hydrolysis, the total slurry was centrifuged at $18000 \mathrm{~g}$ for $15 \mathrm{~min}$, and the liquid part was mixed with activated carbon (Fisher Scientific \#05-690A) in the ratio of $5 \mathrm{~g}$ of activated carbon to $100 \mathrm{~mL}$ of hydrolysate and then incubated at $50{ }^{\circ} \mathrm{C}$ for $1 \mathrm{~h}$ in an unbaffled flask under shaking at $150 \mathrm{rpm}$. After centrifugation, yeast nitrogen base (YNB) (Sigma-Aldrich) and urea were added into the supernatant at final concentrations of $1.67 \mathrm{~g} \mathrm{~L}^{-1}$ and $2.27 \mathrm{~g} \mathrm{~L}^{-1}$, respectively. Subsequently, the solution was centrifuged at $18000 \mathrm{~g}$ for $15 \mathrm{~min}$, and the supernatant was sterilized with a $0.22 \mu \mathrm{m}$ filter.

\subsection{Preparation of hydrolysate with a pH adjustment of 5.5}

When hydrolysis was done, the slurry was centrifuged at $18000 \mathrm{~g}$ for $15 \mathrm{~min}$, and the supernatant was mixed with YNB and urea. The final concentrations of YNB and urea were $1.67 \mathrm{~g} \mathrm{~L}^{-1}$ and $2.27 \mathrm{~g} \mathrm{~L}^{-1}$, respectively. The $\mathrm{pH}$ was adjusted to 5.5 with the addition of $\mathrm{NaOH}$ pellets, and then the hydrolysate was sterilized with a $0.22 \mu \mathrm{m}$ filter.

\subsection{Yeast strain and seed culture preparation}

Xylose-fermenting Saccharomyces cerevisiae GLBRC Y73, ${ }^{\mathbf{4 0}}$ a yeast strain genetically modified to convert xylose into ethanol, was obtained from Trey Sato, University of WisconsinMadison. To prepare the seed culture, the strain was grown on a YEPD $\left(10 \mathrm{~g} \mathrm{~L}^{-1}\right.$ yeast extract, $20 \mathrm{~g} \mathrm{~L}^{-1}$ peptone, $20 \mathrm{~g} \mathrm{~L}^{-1}$ glucose) plate at $30^{\circ} \mathrm{C}$ for 1 day. The cells were transferred to the liquid YEPD medium in an unbaffled flask. The seed was grown overnight at $30^{\circ} \mathrm{C}$ under $150 \mathrm{rpm}$ agitation.

\subsection{Ethanolic fermentation}

Fermentation experiments were conducted using a working volume of $50 \mathrm{~mL}$ in a $250 \mathrm{~mL}$ unbaffled flask at $30{ }^{\circ} \mathrm{C}$ under $150 \mathrm{rpm}$ agitation. A designated volume of seed culture was centrifuged at $5000 \mathrm{rpm}$ for $5 \mathrm{~min}$, and a yeast cell pellet was resuspended in the medium to initiate fermentation. The flasks were capped with fermentation locks (Bacchus \& Barleycorn 


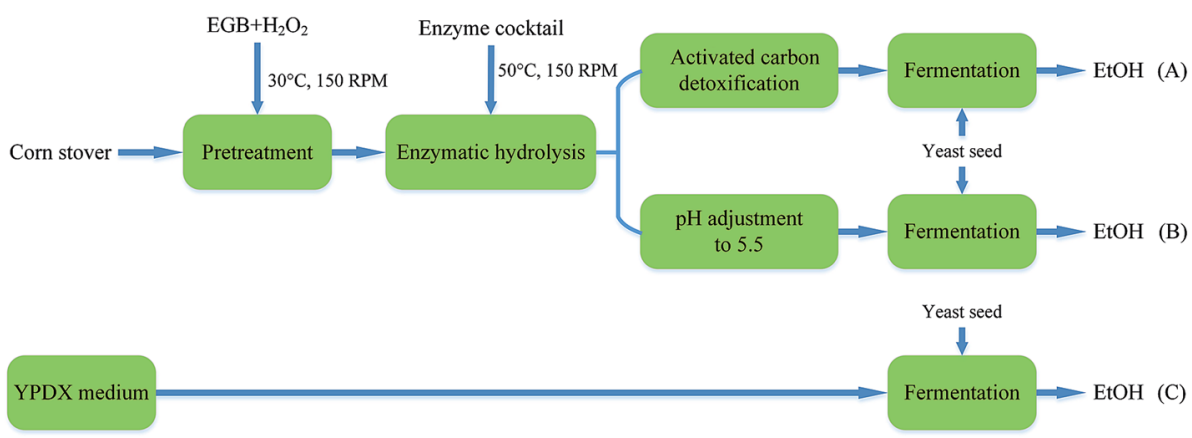

Fig. 1 A schematic diagram of ethanol production from: pretreated CS hydrolysate detoxified using activated carbon (A); and hydrolysate at $\mathrm{pH}$ 5.5 (B); with YPDX medium (C) for comparison.

Ltd., Shawnee, KS). $\mathrm{N}_{2}$ was used for purging to maintain anaerobic conditions in the flasks. Samples were taken during the course of fermentation. Three different approaches were employed. As shown in Fig. 1, in the first approach, the pretreated CS hydrolysate was detoxified using activated carbon (Fig. 1A). In the second approach, the hydrolysate was adjusted to $\mathrm{pH} 5.5$ using $\mathrm{NaOH}$ pellets (Fig. 1B). In the third approach, YPDX medium was used instead of CS hydrolysate (Fig. 1C) for comparison.

\subsection{Determination of monosaccharides, ethanol and yeast cells}

The CS composition was determined based upon the standard method, "Determination of Structural Carbohydrates and Lignin in Biomass", described by the National Renewable Energy Laboratory. ${ }^{41}$ The monosaccharides and ethanol were analyzed using a BioRad Aminex HPX-87H column at $65^{\circ} \mathrm{C}$ with a constant flow rate of $0.6 \mathrm{~mL} \mathrm{~min}^{-1}$ using $5 \mathrm{mM}$ sulfuric acid as the mobile phase. All composition experiments were performed in triplicate. The optical densities of the cells were determined using a spectrophotometer (Shimadzu SPD-20A, Japan) at a wavelength of $600 \mathrm{~nm}$ after proper dilution with deionized water to give an absorbance range of $0.20-0.80$. Un-inoculated fermentation medium was used as a blank.

\section{Results and discussion}

\subsection{Alkaline oxidative pretreatment of corn stover using an EGB}

Fig. 2A and B show a visual comparison of raw corn stover (CS) material and alkaline oxidative pretreated CS. Obviously, the biomass changed to a lighter color after pretreatment. At the same time, the pretreated biomass was swelled compared with the raw material, which indicates that its porosity increased; this could enhance the enzyme accessibility and sugar digestibility, which will be further discussed later.

Besides the changes in appearance, the chemical composition also changed during pretreatment. All the pretreated samples exhibited higher cellulose and lower lignin content than the untreated ones (Table 1), which could be attributed to the removal of lignin during pretreatment, as $56.6 \%$ of the original lignin was solubilized (from $20.7 \%$ to $9.0 \%$ ) after $6 \mathrm{~h}$ pretreatment (Fig. 2C). Fig. 2C clearly shows that during the first $3 \mathrm{~h}$ of pretreatment, $51.2 \%$ of the lignin was solubilized (from $20.7 \%$ to $10.1 \%$ ), and only $35.7 \%$ of the lignin (from $20.7 \%$ to $7.4 \%$ ) was retained in the insoluble part after pretreatment for
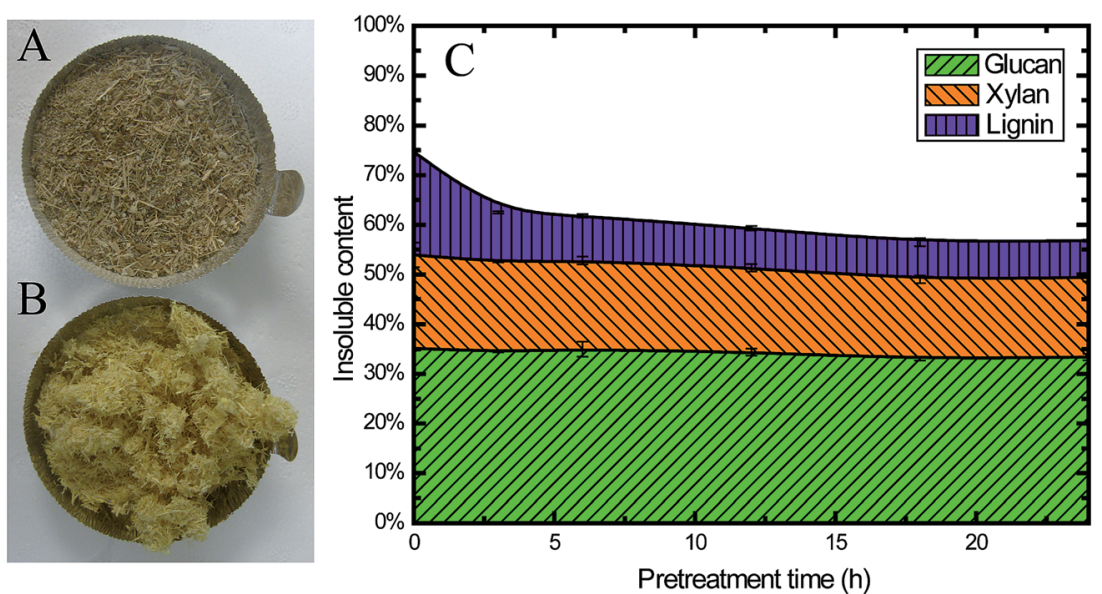

Fig. 2 Characteristics of CS pretreated using EGB: photographs of untreated (A) and treated (B) CS, and (C) the insoluble content of CS during pretreatment. 
Table 1 Chemical compositions of the untreated and pretreated CS

\begin{tabular}{|c|c|c|c|c|c|}
\hline & $0 \mathrm{~h}$ & $6 \mathrm{~h}$ & $24 \mathrm{~h}$ & $32 \mathrm{~h}$ & $48 \mathrm{~h}$ \\
\hline Glucan & $34.1 \% \pm 3.7 \%$ & $44.0 \% \pm 2.2 \%$ & $44.2 \% \pm 4.8 \%$ & $46.0 \% \pm 0.7 \%$ & $46.5 \% \pm 1.1 \%$ \\
\hline Xylan & $22.7 \% \pm 0.1 \%$ & $24.8 \pm 1.2 \%$ & $25 \pm 1.7 \%$ & $24.7 \% \pm 0.1 \%$ & $24.7 \% \pm 0.9 \%$ \\
\hline
\end{tabular}

$24 \mathrm{~h}$. These findings were consistent with previous studies on alkaline pretreated residues. ${ }^{42}$ Alkaline chemicals, such as $\mathrm{NaOH}$, have been known to remove lignin from the biomass cell wall matrix by reacting with the carboxylic acid and phenolic groups of lignin, making them more alkali soluble. ${ }^{42}$

This alkaline oxidative pretreatment did not have a significant impact on cellulose. Only $2.5 \%$ of the total glucan was solubilized. At the same time, $15.7 \%$ of the hemicellulose was released into the pretreatment slurry (Fig. 2C). This result was also consistent with previous studies. ${ }^{6}$ The reaction occurred mainly in the initial stages, especially within the first $3 \mathrm{~h}$. This pretreatment method retained most of the cellulose and hemicellulose in the solid fraction after pretreatment, which is one of the important advantages of alkaline oxidative pretreatment.

\subsection{Enzymatic hydrolysis}

To investigate the digestibility after pretreatment, we performed enzymatic saccharification on $24 \mathrm{~h}$ pretreated CS under the conditions of $2 \%(\mathrm{w} / \mathrm{v})$ biomass loading. Within $24 \mathrm{~h}$, the glucan conversion reached $84 \%$, and then it was slowly increased to $97 \%$ after $72 \mathrm{~h}$. The glucan conversion for the pretreated CS was 3.8, 3.7 and 3.7 times higher than raw CS after $24 \mathrm{~h}, 48 \mathrm{~h}$ and $72 \mathrm{~h}$, respectively (Fig. 3A). This result demonstrated that pretreatment with an EGB could effectively enhance the digestibility.

We also performed pretreatment and hydrolysis at a higher biomass loading $(20.5 \%, \mathrm{w} / \mathrm{w})$ in order to obtain a higher ethanol titer after fermentation. Fig. 3B shows the hydrolysis results for samples taken after different pretreatment times, where the duration of hydrolysis was $24 \mathrm{~h}$. We found that pretreatment increased both glucan and xylan conversion, especially during the initial $3 \mathrm{~h}$. After $12 \mathrm{~h}$ pretreatment, the conversion was gradually increased, reaching a plateau after $18 \mathrm{~h}$. This result suggested that pretreatment of $18 \mathrm{~h}$ or less was enough for ideal conversion, which is similar to many other reports of alkaline pretreatment with $\mathrm{NaOH} .^{6}$

It is well recognized that lignin content and distribution affect enzymatic saccharification. ${ }^{\mathbf{4 3 , 4 4}}$ High cellulose digestibility has been obtained from extensively delignified softwood. ${ }^{44}$ Our results (Fig. 2C, 3A and B) demonstrated that alkaline oxidative pretreatment enhanced the enzymatic digestibility of lignocellulosic biomass through removing lignin. ${ }^{5}$ In the enzymatic saccharification stage, the lignin content remained constant because there was no lignin degradation. Simultaneously, $70 \%$ of the cellulose and $49 \%$ of the hemicellulose were degraded, and monomeric sugars were released into the liquid phase (Fig. 3C).

\subsection{Ethanolic fermentation}

The presence of inhibitors in hydrolysates is a major obstacle to cellulosic ethanol production because these inhibitors negatively affect the performance of microorganisms. It is well known that inhibitors, which are toxic to microorganisms during fermentation, are generated during the pretreatment process, no matter which pretreatment method is used for the bioconversion of lignocellulose. Ferulic acid, $p$-coumaric acid, acetic acid, formic acid and other phenolic compounds are common inhibitors generated during alkaline oxidative pretreatment. ${ }^{40}$ Usually, some detoxification procedures are necessary prior to fermentation, such as biological methods, physical methods, chemical methods and combined treatments. ${ }^{45,46}$ In this study, fermentation was conducted with different media, including a synthetic medium and hydrolysates treated via different detoxification procedures (Fig. 1). Glucose could be entirely utilized in less than $16.5 \mathrm{~h}$ with the pure sugar (glucose \& xylose) medium (YPDX), and then xylose could be efficiently used and converted to ethanol (Fig. 4A and Table 2). For the lignocellulosic hydrolysate, two detoxification methods were employed in the present study. Fig. 4B shows the fermentation profile of hydrolysate detoxified via activated carbon. The lag phase of yeast growth was much longer compared with the synthetic medium, and this might explain why the glucose uptake rate was slower compared with the synthetic medium. It took $24 \mathrm{~h}$ to utilize all the glucose, and then xylose was converted to yeast cell biomass and ethanol. Fig. 4C and Table 2 illustrate the fermentation results for the hydrolysate at $\mathrm{pH}$ 5.5. The glucose uptake and utilization profile is very similar to that of the synthetic medium. The xylose-toethanol conversion rate was between that of the synthetic medium and the hydrolysate treated with activated carbon.

In this study, we assessed the effects of inhibitors on fermentation, and the effectiveness of inhibitor removal was also examined from different detoxification methods. The activated carbon detoxification method was able to remove some of the inhibitors. The main inhibitory compounds, lignin derived ferulic acid and $p$-coumaric acid, were removed 100\% and $93.0 \%$, respectively (Fig. 5). However, there was also sugar loss after activated carbon detoxification, and this was most probably due to adsorption. For CS, the losses of glucose, xylose and arabinose were $4.7 \%, 9.8 \%$ and $9.5 \%$, respectively (Fig. 5). In order to verify this characteristic, switchgrass was used to conduct the same experiment. When using switchgrass, the 
A

$\mathrm{B}$

C
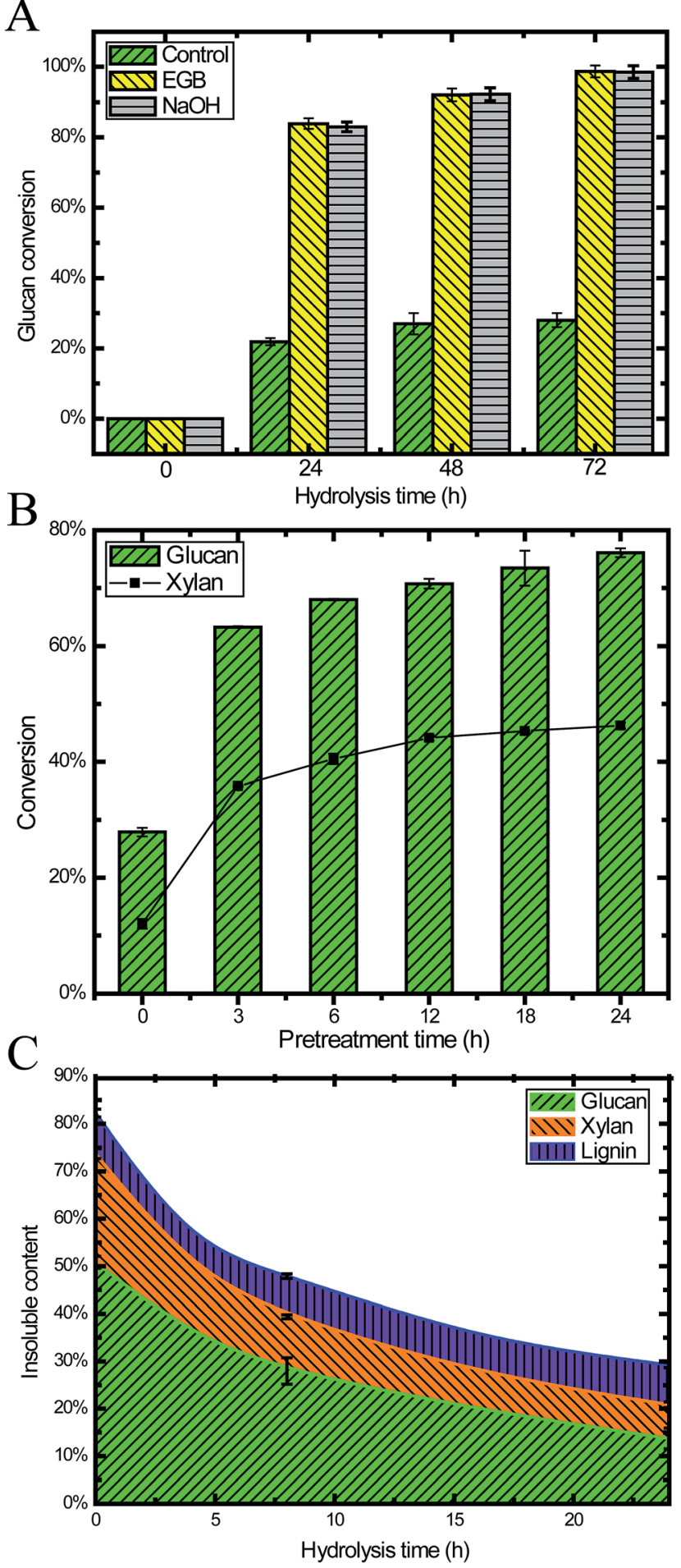

Fig. 3 Profiles of the enzymatic hydrolysis of pretreated CS: (A) cellulose conversion during hydrolysis for both raw and pretreated CS ( $2 \%$ biomass loading, w/v); (B) $24 \mathrm{~h}$ hydrolysis of pretreated CS after different pretreatment times (20.5\% biomass loading, $\mathrm{w} / \mathrm{w})$; and $(\mathrm{C})$ the insoluble content of CS during enzymatic hydrolysis.

losses of these three monomeric sugars were $8.6 \%, 11.2 \%$ and $8.5 \%$, respectively. Venkatesan ${ }^{47}$ has reported sugar losses for hydrolysate detoxified using activated carbon, which is consistent with our results.
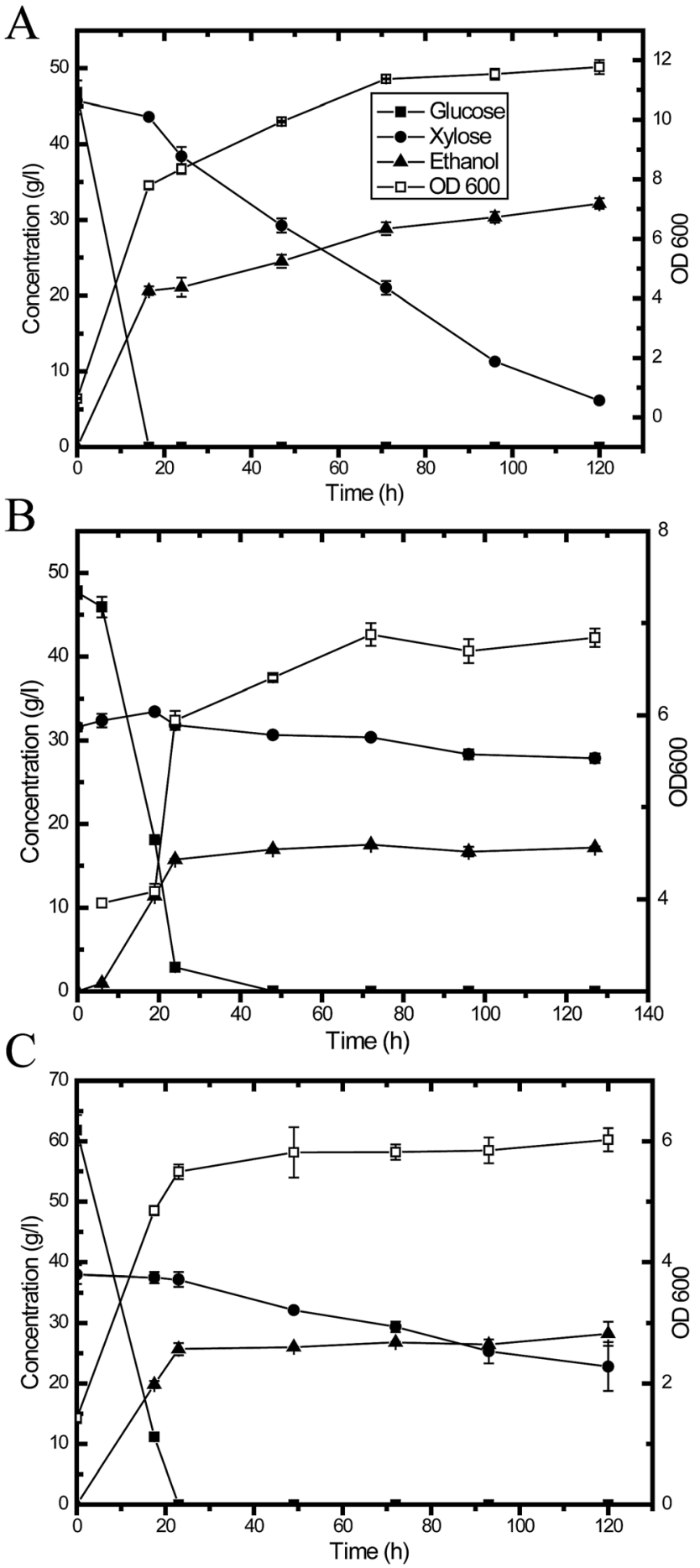

Fig. 4 Y73 fermentation profiles under different conditions: (A) synthetic medium (YPDX); (B) CS hydrolysate detoxified using activated carbon; and (C) CS hydrolysate at $\mathrm{pH} 5.5$.

Besides ferulic acid and $p$-coumaric acid, acetic acid is another important inhibitor generated during alkaline oxidative pretreatment. Acetic acid inhibits the growth of yeast cell mass, sugar consumption and ethanol volumetric productivity. ${ }^{48}$ Fig. 5 reveals that activated carbon detoxification did not remove much acetate, while the concentration of undissociated acetic acid was decreased when the medium $\mathrm{pH}$ was increased 
Table 2 Summary of parameters for fermentation experiments with different hydrolysates and a synthetic medium

\begin{tabular}{llll}
\hline Medium & $\begin{array}{l}\text { Hydrolysate detoxified } \\
\text { using activated carbon }\end{array}$ & $\begin{array}{l}\text { Hydrolysate } \\
\text { at pH 5.5 }\end{array}$ & $\begin{array}{l}\text { Synthetic medium } \\
\text { (YPDX) }\end{array}$ \\
\hline Initial glucose $\left(\mathrm{g} \mathrm{L}^{-1}\right)$ & $47.7 \pm 0.8$ & $77.4 \pm 0.3$ & $46.6 \pm 1.8$ \\
Initial xylose $\left(\mathrm{g} \mathrm{L}^{-1}\right)$ & $31.6 \pm 0.5$ & $35.7 \pm 0.5$ & $45.7 \pm 0.5$ \\
Ethanol yield from xylose & $\mathrm{NA}$ & 0.2 & 0.3 \\
Xylose consumption & $11.7 \%$ & $56.7 \%$ & $86.6 \%$ \\
Y/x/s $^{a}$ & $0.2 \pm 0$ & $0.2 \pm 0.0$ & $0.3 \pm 0$ \\
Sugar consumption $(\%)^{b}$ & 64.8 & 85.6 & 94.3 \\
${\text { Ethanol metabolic yield }(\%)^{c}}$ & 64.6 & 72.4 & 74.4
\end{tabular}

${ }^{a} \mathrm{Y} / \mathrm{x} / \mathrm{s}$ : cell biomass yield on glucose was calculated based on the maximum cell biomass during glucose fermentation and the consumed glucose at that time. ${ }^{b}$ Sugar consumption was calculated based on the available monomeric glucose and xylose for fermentation. ${ }^{c}$ Ethanol yield calculated based on the total consumed glucose and xylose, and the theoretical ethanol yield was assumed to be $0.51 \mathrm{~g} \mathrm{~g}^{-1}$ of sugar.

to 5.5. This finding suggested that a higher $\mathrm{pH}$ could alleviate the inhibitory effects of acetic acid on S. cerevisiae fermentation and enhance the ethanol production (Fig. 5B and C). This result also confirmed that the inhibitory effects of acetic acid were linked to the undissociated form of acetic acid, which was consistent with previous reports. ${ }^{48}$ Overall the hydrolysate with $\mathrm{pH}$ adjustment performed better than the hydrolysate detoxified with activated carbon.

Adjusting the hydrolysate $\mathrm{pH}$ also showed better performance than activated carbon detoxification in terms of the consumption of glucose and xylose, as well as ethanol metabolic yield. Although it is well acknowledged that activated carbon can efficiently remove phenolic compounds, ${ }^{6,40,49}$ presumably there were still some other types of unknown inhibitors in the hydrolysate, which might exert negative effects on sugar consumption and conversion. Moreover, sugar loss was inevitable because of the activated carbon adsorption. For all of these reasons, $\mathrm{pH}$ adjustment to 5.5 was preferable over detoxification with activated carbon.

Compared with previously reported data, ${ }^{6,9,11,19,20}$ the EGB achieves similar performance in biomass pretreatment,

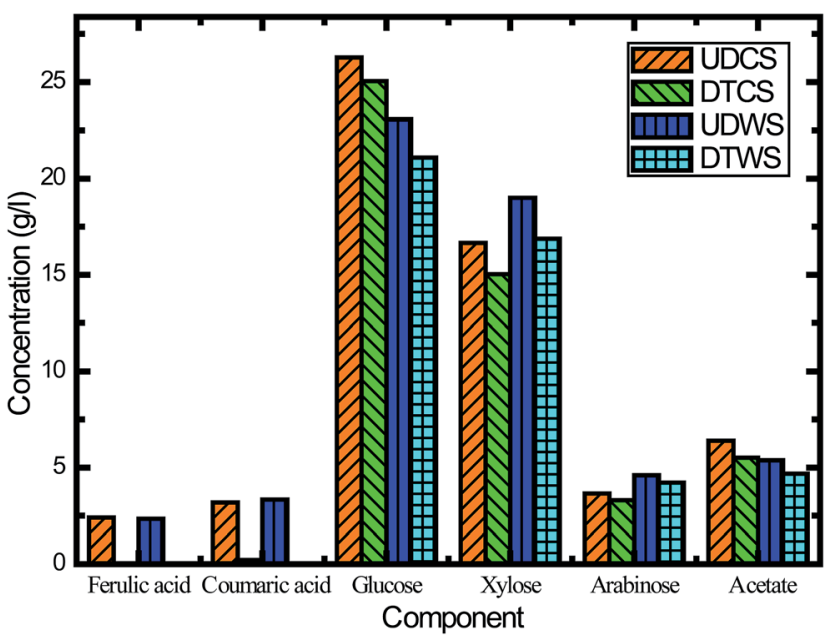

Fig. 5 Hydrolysate component changes in the detoxification step using activated carbon. UDCS: undetoxified corn stover; DTCS: detoxified corn stover; UDSG: undetoxified switchgrass; and DTSG: detoxified switchgrass. enzymatic hydrolysis and ethanol fermentation. Lignin was removed by $56.6 \%$ during $24 \mathrm{~h}$ pretreatment. More than $97 \%$ of the cellulose was converted into glucose under conditions of $2 \%$ biomass loading after $24 \mathrm{~h}$. Moreover, the ethanol metabolic yield was $72.4 \%$, if the $\mathrm{pH}$ of the hydrolysate was adjusted to 5.5 . All of these findings demonstrated that the EGB was a good alternative to $\mathrm{NaOH}$ in alkaline oxidative pretreatment for cellulosic ethanol production.

\subsection{Outlook: biorefinery concept based on this biomass pretreatment}

Based on this new approach of biomass pretreatment with an EGB, we propose a new biorefinery concept for water electrolysis, biological conversion and thermochemical/catalytic conversion (Fig. 6). Water electrolysis can utilize renewable electricity from solar or wind to produce bases, acids and hydrogen. ${ }^{50}$ Hydrogen can be used for hydroprocessing in biomass thermochemical/catalytic conversion, which can produce gasoline, diesel and jet fuel, or valuable chemicals. Normally, hydrogen is produced from the steam reforming of petroleum hydrocarbons, mainly natural gas, which is more economical at large scale production. It would be very attractive to generate hydrogen with scalable water electrolysis technology at a biorefinery site, especially using renewable electricity. ${ }^{51}$

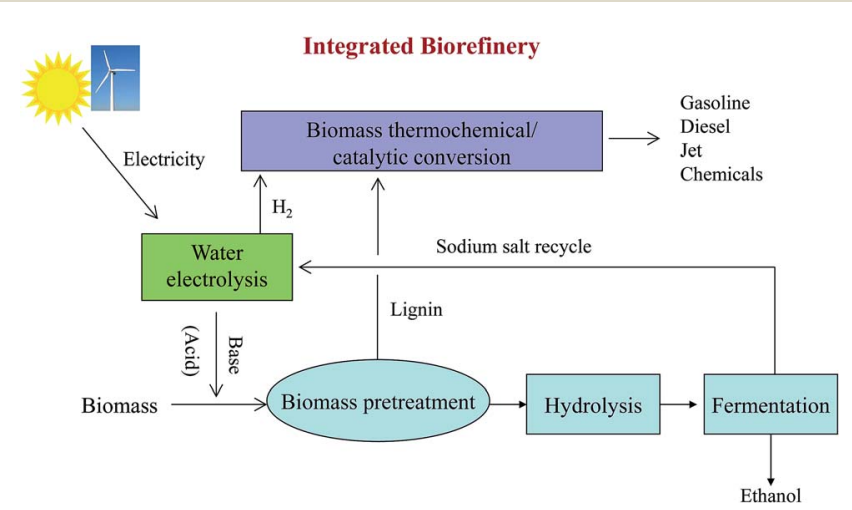

Fig. 6 An integrated biorefinery based on water electrolysis, biological conversion and thermochemical/catalytic conversion. 
Another great benefit is significantly reducing $\mathrm{CO}_{2}$ emission by replacing natural gas derived hydrogen with water electrolysis.

Both an EGB and electrogenerated acid can be used for biomass pretreatment. When alkaline oxidative pretreatment is employed, an EGB is used in the pretreatment step and an electrogenerated acid can be used to adjust the $\mathrm{pH}$ to the optimal conditions for cellulase and hemicellulase prior to hydrolysis. In the case of acid pretreatment, the electrogenerated acid can be used in biomass pretreatment, and the base can be employed to adjust the $\mathrm{pH}$ for enzymatic saccharification and fermentation. The salt needed for water electrolysis (such as $\mathrm{NaCl}$ ) can be recycled after fermentation. Lignin, separated after pretreatment, can be converted into transportation fuels or chemicals via the thermochemical/catalytic conversion process. Residual char from pyrolysis can be used to effectively detoxify hydrolysates by adsorbing aromatic inhibitors of fermentation. ${ }^{6,49}$

\section{Conclusions}

In the present study, we demonstrated that an EGB from water electrolysis, a good alternative to $\mathrm{NaOH}$, could be used for biomass alkaline oxidative pretreatment and the production of ethanol after further hydrolysis and fermentation. High digestibility was achieved in the biomass pretreated with the EGB. Water electrolysis is a promising approach for generating hydrogen, and its byproduct base can be used for biomass pretreatment to produce fuel ethanol and other value added chemicals.

\section{Conflicts of interest}

There are no conflicts of interest to declare.

\section{Acknowledgements}

Part of the study was done in Dr David Hodge's lab in the Department of Chemical Engineering and Materials Science, Michigan State University. The authors are also grateful to Dr Trey Sato in GLBRC, University of Wisconsin-Madison for providing yeast strain Y73. This work was supported by the Natural Science Foundation of Shandong Province (grant number ZR2014BM031) and the Major Research \& Development Program of Shandong Province (grant number 2015GSF121022).

\section{Notes and references}

1 A. Kallioinen, Development of pretreatment technology and enzymatic hydrolysis for biorefineries, http://www.vtt.fi/ Documents/2014_S56.pdf, accessed 22 April 2017.

2 P. Kumar, D. M. Barrett, M. J. Delwiche and P. Stroeve, Ind. Eng. Chem. Res., 2009, 48, 3713-3729.

3 V. Menon and M. Rao, Prog. Energy Combust. Sci., 2012, 38, 522-550.

4 H. Xu, B. Li and X. Mu, Ind. Eng. Chem. Res., 2016, 55, 86918705.
5 T. Liu, D. L. Williams, S. Pattathil, M. Li, M. G. Hahn and D. B. Hodge, Biotechnol. Biofuels, 2014, 7, 48.

6 G. Banerjee, S. Car, T. Liu, D. L. Williams, S. L. Meza, J. D. Walton and D. B. Hodge, Biotechnol. Bioeng., 2012, 109, 922-931.

7 B. C. Saha and M. A. Cotta, Biotechnol. Prog., 2006, 22, 449453.

8 P. Martel and J. M. Gould, J. Appl. Polym. Sci., 1990, 39, 707714.

9 J. M. Gould, B. K. Jasberg, G. J. Fahey and L. L. Berger, Biotechnol. Bioeng., 1989, 33, 233-236.

10 M. S. Kerley, G. J. Fahey, L. L. Berger, J. M. Gould and B. F. Lee, Science, 1985, 230, 820-822.

11 J. M. Gould, Biotechnol. Bioeng., 1985, 27, 225-231.

12 J. M. Gould and S. N. Freer, Biotechnol. Bioeng., 1984, 26, 628-631.

13 D. P. Maurya, A. Singla and S. Negi, Biotech., 2015, 5, 597609.

14 R. J. Stoklosa, P. O. A. Del, C. S. L. Da, N. Uppugundla, D. L. Williams, B. E. Dale, D. B. Hodge and V. Balan, Bioresour. Technol., 2017, 226, 9-17.

15 Y. C. Park and J. S. Kim, Energy, 2012, 47, 31-35.

16 R. Sharma, V. Palled, R. R. Sharma-Shivappa and J. Osborne, Appl. Biochem. Biotechnol., 2013, 169, 761-772.

17 Y. Jin, T. Huang, W. Geng and L. Yang, Bioresour. Technol., 2013, 137, 294-301.

18 Y. Chen, M. A. Stevens, Y. Zhu, J. Holmes and H. Xu, Biotechnol. Biofuels, 2013, 6, 8.

19 G. Banerjee, S. Car, J. S. Scott-Craig, D. B. Hodge and J. D. Walton, Biotechnol. Biofuels, 2011, 4, 16.

20 J. M. Gould, Biotechnol. Bioeng., 1984, 26, 46-52.

21 G. D. Saratale and M. Oh, RSC Adv., 2015, 5, 97171-97179.

22 Z. Yuan, Y. Wen and N. S. Kapu, Bioresour. Technol., 2018, 247, 242-249.

23 L. J. Jonsson and C. Martin, Bioresour. Technol., 2016, 199, 103-112.

24 J. H. P. Utley, in Topics in Current Chemistry, ed. E. Steckhan, Springer, Berlin, 2005, pp. 131-165.

25 S. K. Green, J. Lee, H. J. Kim, G. A. Tompsett, W. B. Kim and G. W. Huber, Green Chem., 2013, 15, 1869-1879.

26 N. Singh, Y. Song, O. Y. Gutiérrez, D. M. Camaioni, C. T. Campbell, J. A. Lercher and M. Abdelrahim, ACS Catal., 2016, 6, 7466-7470.

27 C. H. Lam, C. B. Lowe, Z. Li, K. N. Longe, J. T. Rayburn, M. A. Caldwell, C. E. Houdek, J. B. Maguire, C. M. Saffron and D. J. Miller, Green Chem., 2015, 17, 601-609.

28 Z. Li, M. Garedew, C. H. Lam, J. E. Jackson, D. J. Miller and C. M. Saffron, Green Chem., 2012, 14, 2540-2549.

29 Z. Li, S. Kelkar, C. H. Lam, K. Luczek, J. E. Jackson, D. J. Miller and C. M. Saffron, Electrochim. Acta, 2012, 64, 87-93.

30 Z. Li, S. Kelkar, L. Raycraft, M. Garedew, J. E. Jackson, D. J. Miller and C. M. Saffron, Green Chem., 2014, 16, 844852.

31 H. J. Kim, J. Lee, S. K. Green, G. W. Huber and W. B. Kim, Chemsuschem, 2014, 7, 1051-1056. 
32 Y. Kwon, S. C. Lai, P. Rodriguez and M. T. Koper, J. Am. Chem. Soc., 2011, 133, 6914-6917.

33 J. C. Yu, M. M. Baizer and K. Nobe, J. Electrochem. Soc., 1988, 135, 83-87.

34 K. Uneyama, A. Isimura, K. Fujii and S. Torii, Tetrahedron Lett., 1983, 24, 2857-2860.

35 C. Carpetis, Int. J. Hydrogen Energy, 1982, 7, 287-310.

36 W. Fan, C. Chen, H. Bai, B. Luo, H. Shen and W. Shi, Appl. Catal., B, 2016, 195, 9-15.

37 A. Kudo and Y. Miseki, Chem. Soc. Rev., 2009, 38, 253-278.

38 X. Chen, S. Shen, L. Guo and S. S. Mao, Chem. Rev., 2010, 110, 6503-6570.

39 Z. Zou, J. Ye, K. Sayama and H. Arakawa, Nature, 2001, 414, 625-627.

40 T. K. Sato, T. Liu, L. S. Parreiras, D. L. Williams, D. J. Wohlbach, B. D. Bice, I. M. Ong, R. J. Breuer, L. Qin, D. Busalacchi, S. Deshpande, C. Daum, A. P. Gasch and D. B. Hodge, Appl. Environ. Microbiol., 2014, 80, 540-554.

41 A. Sluiter, B. Hames, R. Ruiz, C. Scarlata, J. Sluiter, D. Templeton and D. Crocker, Determination of Structural Carbohydrates and Lignin in Biomass, National Renewable Energy Laboratory (NREL), 2011.

42 M. G. Jackson, Anim. Feed Sci. Technol., 1977, 2, 105-130.
43 T. B. Vinzant, C. I. Ehrman, W. S. Adney, S. R. Thomas and M. E. Himmel, Appl. Biochem. Biotechnol., 1997, 62, 99-104.

44 C. A. Mooney, S. D. Mansfield, M. G. Touhy and J. N. Saddler, Bioresour. Technol., 1998, 64, 113-119.

45 S. I. Mussatto and I. C. Roberto, Bioresour. Technol., 2004, 93, 1-10.

46 M. H. Thomsen, A. Thygesen and A. B. Thomsen, Appl. Microbiol. Biotechnol., 2009, 83, 447-455.

47 S. Venkatesan, in Separation and Purification Technologies in Biorefineries, ed. S. Ramaswamy, H. Huang and B. V. Ramarao, John Wiley \& Sons, Ltd, Hoboken, New Jersey, 2013, pp. 101-148.

48 E. Casey, M. Sedlak, N. W. Ho and N. S. Mosier, FEMS Yeast Res., 2010, 10, 385-393.

49 D. B. Hodge, C. Andersson, K. A. Berglund and U. Rova, Enzyme Microb. Technol., 2009, 44, 309-316.

50 Hydrogen Production: Electrolysis, http://energy.gov/eere/ fuelcells/hydrogen-production-electrolysis, accessed 20 March 2017.

51 K. Bullis, Cheap Hydrogen from Sunlight and Water, http:// www.technologyreview.com/s/521671/cheap-hydrogen-fromsunlight-and-water/, accessed 22 April 2017. 